hypersensitivity in the patient. Its disadvantages, the tendency to produce deafness and renal damage, are only evident when it is administered parenterally. It is one of the best antibiotics for local use and as an intestinal antiseptic by the oral route since it is not readily absorbed from the bowel.

The present work, appropriately under the editorship of Dr. Selman A. Waksman, offers a timely account of the information at present available, mainly from American sources, concerning the nature, microbiological aspects, pharmacological properties, and clinical and veterinary uses of neomycin. It is a compilation resulting from a cooperative effort to assemble between the covers of one volume the knowledge and experience of a number of investigators from different centres in the United States. Each chapter is written by one or more of these contributors, but due, no doubt, to careful planning and skilled editing there is little overlap, and the result is a balanced and most readable account of the present state of knowledge on the subject of neomycin, which could hitherto be assessed only by tedious search of the literature.

There is an excellent bibliography in which the references are sensibly collected together instead of being distributed at the end of each chapter (apart from a few supplementaries). Appendixes summarize the specific clinical uses of neomycin and list the preparations containing neomycin with their trade names and indications, compiled from information supplied by the various manufacturing companies, the names and addresses of which are given. This list may serve to correct the impression, which might otherwise be gained from reading the book, that streptomycin is of little interest outside the United States, since the number of foreign manufacturers cited is nearly twice that of firms located in the United States.

J. H. Birkinshaw

\section{A THERMOPHILOUS SHRIMP FROM TUNISIA}

Anatomie und Histo'ogie von Thermosbaena mirabilis Ein Beitrag zur Phylogenie der Reihe Pancarida (Thermosbaenacea). By Dr. Rolf Siewing. 1958. Akademie der Wissenschaften und der Literatur. Abh. Math.-Naturw. Kl. Jahrgang 1957, No. 7 : 197-270, 43 text-figs.

$\mathrm{D}$ . SIEWING'S recent admirable studies on the comparative morphology of the Crustacea Malacostraca have been widely acclaimed and no one is better qualified than he to elucidate the anatomy and histology of Thermosbaena mirabilis Monod. This minute crustacean, first described in 1924, is restricted in its distribution to a few baths, fed by hot springs, at El Hamma, Tunisia. In recent years three subterranean species, belonging to the closely related genus Monodella, have been found in Italy and Yugoslavia. These four species, measuring 1.5-4 $\mathrm{mm}$. in length, are unique among Malacostraca in having a dorsal brood chamber formed by a temporary enlargement of the carapace. Opinion has varied as to the systematic position of the order Thermosbaenacea; it is sometimes referred to the division Peracarida, or placed between the Peracarida and the Syncarida; Sars united it with the Bathynellacea in a new group, the Anomostraca.
The material studied was collected by Dr. Anton Brunn in 1938. A detailed account, accompanied by admirably clear line drawings and microphotographs, is given of each system in turn-vascular, respiratory, nervous, digestive and reproductive. The reconstructions of the general anatomy of male and female are excellent, although an enlargement of the head end of Fig. 1, $A$, with its numerous guide lines, might with advantage have been included. Anatomical peculiarities are fewer than might have been expected. The oviduct opens in the usual Malacostracan position, at the base of the sixth thoracie limb, and there is no dorsally directed branch such as has been claimed for Monodella but not confirmed. Prof. Barker, who collected ovigerous females in September 1950, thinks that during oviposition Thermosbaena lies on its back so that the few large eggs drop into the brood chamber (personal communication). A pair of reduced, though possibly still functional, eyes has been found. Certain features appear to be adaptive, since they are paralleled in other minute cavernicolous or interstitial forms. For example, the extremely short heart is restricted to the first thoracic segment, where it is in intimate association with the respiratory carapace ; in the Bathynellacea, which have no carapace, it lies in the fourth thoracic segment.

An appraisal of the external morphology follows. At times the author is prolix ; for example, his interesting point about the segmentation of the thoracic limbs could have been made in a few paragraphs instead of in a few pages. In the second pair, which are set quite differently on the body and are apparently modified as gnathopods, the ischium has fused completely with the basis. In each of the succeeding limbs (peraeopods) it has almost completely fused with the merus. He concludes that the Thermosbaenacea, though closely related to, must be excluded from, the Peracarida. I am not entirely convinced of the necessity for the new division Pancarida, which is based chiefly on two characters: the structure of the maxillipeds and the dorsal brood chamber. The retention of two endites and the persistence, in some species of Monodella, of exopodite and/or endopodite in the maxilliped suggest, he says, a very primitive position for the Thermosbaenacea. This condition is widespread in the Decapoda and-the coxal endite apart-in Mysidacea. In Monodella, when both rami persist the maxilliped exhibits marked sexual dimorphism, the endopodite being modified to form a clasping organ in the adult male. As to the brood chamber: within the Copepoda certain parasitic forms have abandoned the normal method of carrying the eggs in favour of a carapacial brood chamber, and this has probably occurred independently more than once. Why then is the author so certain that something analogous could not have happened within the Peracarida (pp. 261-263) ? There might be some good reason why, in a minute animal adapted to an extreme biotope, a ventral marsupium composed of oostegites became impracticable (for example, the thoracic limbs might be too short). Owing to the high temperature to which Thermosbaena has become adapted (around $45^{\circ}$ C.) its feeding and locomotor habits would have to be studied in the field. This could only be undertaken by a competent observer who, from previous experience with other minute crustaceans, knew exactly which methods to adopt.

Whether one accepts his conclusions or not, Dr. Siewing is to be congratulated on another excellent piece of research. ISABELLA GORDON 